\title{
Tumor Cell Mobility
}

National Cancer Institute

\section{Source}

National Cancer Institute. Tumor Cell Mobility. NCI Thesaurus. Code C20741.

Any type of motility of a tumor cell that involves translocation of the cell, or cell body, from one site to another; distinct from forms of cell movement that involve only movement of cell processes (e.g., axons, microvilli, etc.). (NCI) 